\title{
Perdas de solo, nutrientes, matéria orgânica e efeitos microestruturais em Argissolo Vermelho-Amarelo sob chuva simulada(1)
}

\author{
Carlos Ernesto Reynaud Schaefer ${ }^{(2)}$, Demétrius David Silva ${ }^{(3)}$, Karlos Welby Neri Paiva(3), \\ Fernando Falco Pruski ${ }^{(4)}$, Manoel Ricardo Albuquerque Filho ${ }^{(5)}$ e Miriam Abreu Albuquerque ${ }^{(6)}$
}

Resumo - Estudo experimental com simulador de chuva foi conduzido em área de Argissolo Vermelho-Amarelo caulinítico, em Viçosa, MG, com intensidade de precipitação de $60 \mathrm{~mm} \mathrm{~h}^{-1}$ e seis aplicações sucessivas, espaçadas de 12 horas. Caracterizou-se a evolução do selamento superficial e das perdas de nutrientes, solo e matéria orgânica em razão de diferentes porcentagens de cobertura $(0,20$, 40,80 e $100 \%$ ) em cultivo morro abaixo (declividade média de $9,5 \%$ ), em resposta à energia cinética decorrente da precipitação. As perdas totais de solo foram superiores a $11 \mathrm{t} \mathrm{ha}^{-1}$ nos tratamentos com porcentagem de cobertura entre 0 e $40 \%$, reduzindo-se a pouco mais de $5 \mathrm{t} \mathrm{ha}^{-1}$ com $80 \%$ até zero no tratamento $100 \%$ coberto com Bidim. As perdas de nutrientes seguiram a ordem $\mathrm{Ca}>\mathrm{Mg}>\mathrm{K}>\mathrm{P}$ e foram correlacionadas às perdas de matéria orgânica. $\mathrm{O}$ fracionamento de substâncias húmicas revelou a concentração residual de humina e perdas seletivas de formas mais solúveis (ácidos fúlvicos) com a enxurrada. A erosão causou heterogeneidade entre a parte superior e inferior das parcelas experimentais. A macroporosidade entre 10 e $20 \mathrm{~cm}$ é maior na parte superior da parcela, sugerindo a migração de argila dispersa e entupimento de macroporos nas condições de chuva simulada. Excetuando-se o tratamento com $100 \%$ de cobertura, todos os demais evidenciam crosta deposicional. Nos tratamentos com maior exposição houve presença de crosta erosional, ao fim do teste de campo.

Termos para indexação: porosidade do solo, permeabilidade, degradação do solo, erosão.

\section{Soil, nutrient and organic matter losses in a Red-Yellow Podzolic under simulated rainfall}

Abstract - The present work was carried out in a kaolinitic Red-Yellow Podzolic at Viçosa, State of Minas Gerais, Brazil, aiming to evaluate the effect of soil cover under simulated rainfall at an intensity of $60 \mathrm{~mm} \mathrm{~h}^{-1}$ on soil, nutrient and organic matter losses, and microstructural effects. The experimental area was set up in a downslope cultivation (average slope of 9.5\%), with five experimental units $(2.0 \times 2.0 \mathrm{~m})$ with a Bidim soil cover of $0,20,40,80$ and $100 \%$. Six successive rainfall applications were made at 12 hours regular intervals, collecting the resulting soil materials after each test. The soil losses were higher than $11 \mathrm{t} \mathrm{ha}^{-1}$ in treatments with cover ranging from 0 to $40 \%$, and about $5 \mathrm{t} \mathrm{ha}^{-1}$ with $80 \%$ cover, and no losses were observed in the $100 \%$ Bidim cover. The nutrient losses followed the order $\mathrm{Ca}>\mathrm{Mg}>\mathrm{K}>\mathrm{P}$ and were correlated to organic matter. The organic matter fractionation revealed a residual concentration of humin and selective loss of soluble forms with runoff. A heterogeneity between the upper and lower parts of the experimental unit, attributable to erosion, was observed. The macroporosity estimated by micromorphology at the $10-20 \mathrm{~cm}$ depth was consistently higher in the upper part of the unit, suggesting clay migration and porosity loss under simulated rainfall. Except for the $100 \%$ cover, all others showed the development of depositional crust, whereas the most exposing treatments also showed the presence of erosional crust, at the end of the tests.

Index terms: soil porosity, permeability, soil degradation, erosion.

\footnotetext{
(1) Aceito para publicação em 20 de setembro de 2001 . Projeto financiado pelo $\mathrm{CNPq}$ e pela Fapemig.

(2) Universidade Federal de Viçosa (UFV), Dep. de Solos, Av. P. H. Rolfs, s/no, Centro, CEP 36571-000 Viçosa, MG Bolsista do CNPq. E-mail: carlos.schaefer@solos.ufv.br

(3) UFV, Dep. de Eng. Agrícola. Bolsista do CNPq. E-mail: david@mail.ufv.br,kpaiva@mail.ufv.br
}

\author{
(4) UFV, Dep. de Eng. Agrícola. E-mail: ffpruski@mail.ufv.br \\ (5)UFV, Dep. de Solos. E-mail: ricardo@solos.ufv.br \\ (6) Fundação Educacional de Caratinga, Centro de Pesquisas, \\ Av. Moacir de Matos 49, Centro, CEP 35300-040 \\ Caratinga, MG. E-mail: miralbuq@funec.br
}




\section{Introdução}

A degradação do solo nos trópicos, embora reconhecido como um problema grave e generalizado, ainda carece de estudos que avaliem aspectos físicos, químicos e ambientais, de forma integrada (Oldeman et al., 1990), especialmente em condições irrigadas (Oldeman, 1994; Lal, 1998). A erosão é um dos principais fatores responsáveis pelo decréscimo na produtividade agrícola, provocando perdas de solo, água e nutrientes. As perdas hídricas e químicas pela enxurrada agrícola podem, ainda, acarretar eutrofização da água (Lal, 1998; Hernani et al., 1999).

O solo cultivado, exposto às chuvas, recebe a maior parte da energia cinética da precipitação, quebrando os agregados e iniciando o processo de erosão. Com a destruição dos agregados, as partículas menores em suspensão penetram e obstruem os poros, diminuindo a permeabilidade e formando o selamento superficial, influenciando a infiltração de água no solo. $\mathrm{O}$ fenômeno do selamento superficial é decorrente da formação de uma camada superficial de maior densidade, pela destruição dos agregados do solo causada pelo impacto das gotas de chuva, dispersão e entupimento dos poros. Tackett \& Pearson (1964) preferem usar o termo crosta superficial, cuja formação é por meio da chuva, e ocorre principalmente em solos intensamente cultivados. Solos com eficiente cobertura vegetal podem reduzir o escoamento laminar, reduzindo as perdas de solo e água (McGregor et al., 1990). O conhecimento preciso da resposta erosiva dos solos sob condições de chuva simulada é importante na predição de perdas e extrapolação para solos e condições semelhantes.

Vários pesquisadores estudaram o selamento superficial quanto à sua formação, caracterização, constituição e suas implicações no manejo do solo e da água. McIntyre (1958), em estudos pioneiros com amostras desestruturadas submetidas à chuva simulada, detectou significantes decréscimos na velocidade de infiltração básica de água decorrente da formação de uma crosta na superfície do solo. Tackett \& Pearson (1964) caracterizaram crostas e amostras para a resistência à penetração e permeabilidade à água, indicando diferenças microestruturais na natureza das crostas e das superfícies compactadas das amostras. Crostas superficiais formadas pela chuva simulada são extremamente densas e de espessura de 1 a $3 \mathrm{~mm}$, formadas por argila orientada. Estudos relacionando o fenômeno de selamento, dinâmica da água e aspectos micropedológicos não são comuns (Tanaka et al., 1992; Bresson \& Valentin, 1994), particularmente nos trópicos (Faria et al., 1998).

Diversos autores reportam que as práticas de manejo mais conservacionistas reduzem as perdas de solos, água e nutrientes, tanto sob chuva simulada (Vieira et al., 1978; Amado et al., 1989; Braida, 1994) quanto natural (Sidiras et al., 1984; Wildner, 1985; Roth et al., 1986; Lombardi Neto et al., 1988; Alves et al., 1995; Faria et al., 1998; Hernani et al., 1997, 1999). Os efeitos da formação ou selamentos superficiais nos processos erosivos têm sido documentados por vários autores (McIntyre, 1958; Bradford et al., 1987; Bertol et al., 1989; Bertoni \& Lombardi Neto, 1990; Bresson \& Valentin, 1994). Contudo, nota-se uma carência de estudos sob condições de chuva simulada em condições tropicais.

Este trabalho objetivou determinar as perdas de solos, nutrientes, matéria orgânica, em seus aspectos qualitativos e quantitativos, como também avaliar os efeitos microestruturais da formação do selamento, sob chuva simulada e em condições de cultivo morro abaixo, com 9,5\% de declividade média.

\section{Material e Métodos}

O experimento foi conduzido em condições de morro abaixo, em Argissolo Vermelho-Amarelo, na estação experimental do Departamento de Fitotecnia da Universidade Federal de Viçosa, MG, no período de janeiro de 1998. A área escolhida representa uma pedopaisagem comumente cultivada em regime de agricultura familiar na Zona da Mata, especialmente com milho e feijão, com a ocorrência generalizada de selamento superficial. Os ensaios foram realizados com a utilização de um simulador de chuvas de braços rotativos, equipado com bocais tipo Vee-jet 80100 , conforme o modelo da Universidade de Nebraska, USA. A intensidade de precipitação aplicada foi de $60 \mathrm{~mm} \mathrm{~h}^{-1}$, com seis aplicações sucessivas, espaçadas no tempo de 12 horas, a fim de caracterizar a evolução do selamento superficial, perdas de solo, nutrientes e matéria orgânica, em razão de diferentes porcentagens de cobertura em resposta à energia cinética decorrente da precipitação. A energia cinética da precipitação aplicada pelo simulador de chuvas 
de braços rotativos foi determinada pela equação de Wischmeier \& Smith (Tossel et al., 1990).

$\mathrm{E}_{\mathrm{w}}=17,124+5,229 \log \mathrm{I}$

em que:

$\mathrm{E}_{\mathrm{w}}=$ energia cinética da precipitação $\left(\mathrm{J} \mathrm{m}^{-2} \mathrm{~mm}^{-1}\right)$;

$\mathrm{I}=$ intensidade de precipitação $\left(\mathrm{mm} \mathrm{h}^{-1}\right)$.

No experimento reportado, o valor de intensidade máxima média ( $\mathrm{i}_{\mathrm{m}}$ ) empregado foi de $60 \mathrm{~mm} \mathrm{~h}^{-1}$, associado a uma duração de precipitação de 68 minutos. Essa combinação foi obtida pela relação entre intensidade-duraçãofreqüência da precipitação, determinada por Pinto (1995) para a cidade de Viçosa, MG. O teste foi realizado em uma área delimitada de um quadrado de oito metros de lado, inscrito na circunferência formada pelos tubos radiais do simulador. Esta área foi isolada a montante por diques para impedir a entrada de água de enxurrada proveniente das áreas vizinhas (Figura 1).

Considerando-se que a condição crítica para a ocorrência de escoamento superficial e perdas de solo é aquela em que o solo se encontra saturado (antes da incidência da chuva de projeto), aplicou-se, antes do início do teste, uma lâmina d'água de $100 \mathrm{~mm}$ no solo, por meio de simulador de chuvas. Para evitar a formação de selamento superficial decorrente dessa precipitação, toda a superfície do solo das parcelas experimentais foi coberta por uma manta sintética de alta permeabilidade (Bidim OP 30), com o objetivo de absorver a energia cinética das gotas d'água. As parcelas experimentais, delimitadas por chapas metálicas, possuíam uma área de 2,0 x 2,0 m e as fileiras de plantio, substituídas pelo Bidim, foram espaçadas de $0,5 \mathrm{~m}$. A condição de manejo analisada foi de preparo convencional do solo e cultivo morro abaixo, de seis parcelas experi-

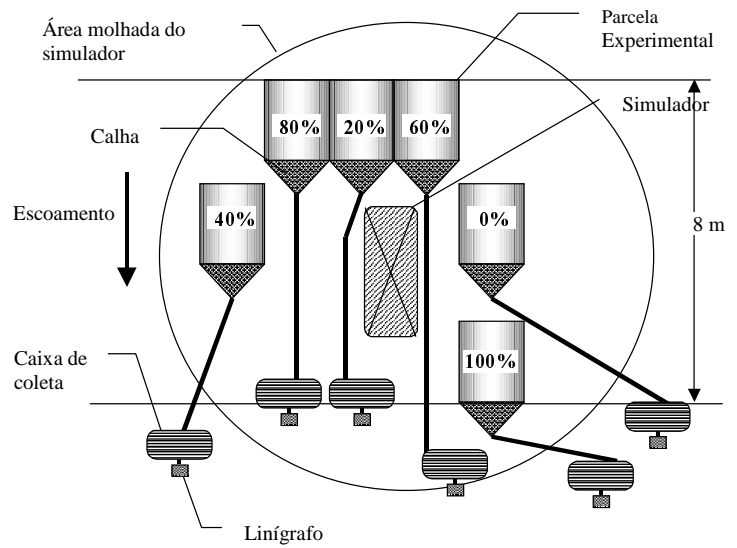

Figura 1. Esquema ilustrando a distribuição espacial do experimento para a determinação do escoamento superficial e perdas de solo. mentais com declividade média de $9,5 \%$, correspondentes a $0,20,40,80$ e $100 \%$ de cobertura do solo (Figura 1). Para o total de seis aplicações, foram realizadas seis coletas subseqüentes de solo e água. Na apresentação dos resultados, foram calculadas as médias das três primeiras coletas e das três últimas.

O solo em que foi realizado o experimento é classificado como Argissolo Vermelho-Amarelo, do qual coletaramse amostras nas profundidades de 0 a 20,20 a 30 e $30 \mathrm{a} 40 \mathrm{~cm}$, as quais foram analisadas quanto às suas características físicas e químicas (Tabelas 1 e 2).

Foram também coletadas amostras indeformadas de solo nas profundidades de 0 a 10, 10 a 20 e 20 a $30 \mathrm{~cm}$, as quais foram submetidas a tensões de 9,8, 29,4, 98,0, 294,0, 980,0 e 1.470,0 kPa para a obtenção da curva de retenção de água no solo. Os conteúdos de umidade retidos nas amostras de solo submetidas às referidas tensões são representados na Figura 2.

As perdas de solo foram determinadas pelo método direto (Bertoni \& Lombardi Neto, 1990), por meio da coleta do solo transportado por arrastamento superficial nas caixas de cada parcela experimental. Em cada caixa de coleta foi instalada uma armação de madeira com tela perfurada, sobre a qual colocou-se uma manta de Bidim para possibilitar a coleta das partículas de solo transportadas após cada uma das aplicações. O solo coletado foi levado a estufa $\left(105^{\circ} \mathrm{C}\right.$ por 24 horas $)$ e posteriormente determinado o seu peso seco. Este método é o mais recomendado e acessível para estudar o efeito global das características do solo, da cobertura vegetal, das práticas culturais e, especialmente, das práticas conservacionistas.

Foram utilizadas amostras para análise do teor de carbono orgânico, além das análises químicas, físicas e mineralógicas de rotina, conforme metodologias recomendadas por Klute (1986) e pela Embrapa (1997). $\mathrm{O}$ fracionamento das substâncias húmicas foi realizado pelo método de solubilidade diferencial (Hayes et al., 1989), quantificadas pelo método de determinação do carbono de Yeomans \& Bremner (1988). O fracionamento foi feito tanto na parcela (solo residual), quanto no material coletado (sedimento), considerando as médias das três coletas iniciais e três coletas finais. Os dados foram reportados

Tabela 1. Características físicas do perfil do solo.

\begin{tabular}{cccccc}
\hline $\begin{array}{c}\text { Profundidade } \\
(\mathrm{cm})\end{array}$ & \multicolumn{4}{c}{ Frações granulométricas $(\%)$} & Classe textural \\
\cline { 2 - 5 } & $\begin{array}{c}\text { Areia } \\
\text { grossa }\end{array}$ & $\begin{array}{c}\text { Areia } \\
\text { fina }\end{array}$ & Silte & Argila & \\
\hline $0-20$ & 16 & 18 & 27 & 39 & Franco-argiloso \\
$20-30$ & 18 & 17 & 16 & 49 & Argiloso \\
$30-40$ & 16 & 16 & 26 & 42 & Argiloso \\
\hline
\end{tabular}

Pesq. agropec. bras., Brasília, v. 37, n. 5, p. 669-678, maio 2002 
como porcentuais relativos de cada fração húmica em relação ao carbono total.

O preparo e a descrição de blocos polidos de solos, para fins de determinação do selamento superficial do solo, constou da coleta em tubos de PVC, com $20 \mathrm{~cm}$ de altura e diâmetro de $200 \mathrm{~mm}$, com posterior secagem ao ar, por sete dias. Posteriormente, saturou-se com acetona e impregnou-se com resina de poliéster (Polylite), diluída com estireno, e adicionada de pigmento UV fluorescente (UVITEX OB, Ciba-Geigy). Após a impregnação e polimerização, efetuou-se o corte de uma fatia delgada de solo, com 2 a $4 \mathrm{~mm}$ de espessura, polimento de uma das faces e obtenção dos blocos polidos em duas repetições. Estes foram fotografados em câmara escura, o que permitiu revelar a porosidade e a porcentagem correspondente à matriz de solo. Os dados foram processados em scanner, com posterior manipulação e quantificação usando-se software de processamento de imagens Adobe-photoshop, para padronização da porosidade calculada por meio de filtros. Foram feitas ainda seções finas de solos nos selamentos observados no solo descoberto ( $0 \%$ cobertura) e no solo sob Bidim em 100\% de cobertura, para ilustrar as feições micromorfológicas.

\section{Resultados e Discussão}

As perdas absolutas dos nutrientes foram na ordem: $\mathrm{Ca}^{2+}>\mathrm{Mg}^{2+}>\mathrm{K}^{+}>\mathrm{P}\left(\mathrm{g} \mathrm{ha}^{-1}\right)$, tanto na soma das três coletas iniciais quanto nas três coletas finais (Tabela 3). Esta ordem seqüencial é semelhante à reportada por Hernani et al. (1987), estudando a influência de métodos de limpeza de Latossolo Amarelo em São Paulo, em condições de chuva natural, com ressalva para a inversão entre $\mathrm{K} \mathrm{e} \mathrm{Mg}$, que tenderam a valores muito próximos no presente estudo. A ordem decrescente foi próxima ao conteúdo trocável dos nutrientes no solo original, conforme esperado (Tabela 1).

As perdas de matéria orgânica do solo (MOS) foram variáveis e possivelmente influenciadas pelo conteúdo variável de matéria orgânica do solo na parcela antes do ensaio de simulação de chuva, conforme mencionado anteriormente. De maneira geral, as perdas tenderam à redução do tratamento com $0 \%$ ao tratamento com $80 \%$ de cobertura, com médias respectivas de 64,2 e $17,5 \mathrm{~kg} \mathrm{ha}^{-1}$. As perdas de matéria orgânica do solo apresentaram coeficientes de correlação positivos e com alta significância com o conteúdo de $\mathrm{P}, \mathrm{K}, \mathrm{Ca}$ e Mg nos sedimentos, indicando que a fração orgânica mobilizada pela erosão foi a principal responsável pela perda de nutrientes em condições de chuva simulada. Coeficientes de correlação negativos e com baixa significância entre os valores de $\mathrm{Ca}, \mathrm{Mg}, \mathrm{K}$ e $\mathrm{P}$ e conteúdo de argila do sedimento (Tabelas 4 e 5) corroboram a baixa contribuição dos colóides minerais, de CTC muito baixa (caulinita e oxiidróxidos) e quimicamente pobres à adsorção de elementos trocáveis neste solo e, conseqüentemente, à aparente não associação entre a argila total perdida e as perdas de nutrientes pela erosão.

As perdas absolutas de solos foram elevadas nos três primeiros tratamentos ( 0,20 e $40 \%$ cobertura), com valores entre 11 e 13,2 $\mathrm{t} \mathrm{ha}^{-1}$. Houve forte redução com $80 \%$ de cobertura $\left(5,2 \mathrm{t} \mathrm{ha}^{-1}\right)$ e não houve perdas com $100 \%$ de cobertura (Tabela 4). De maneira geral, as perdas de solos mostraram poucas variações na granulometria entre os tratamentos, com exceção do tratamento de solo totalmente exposto $(0 \%)$, que mostrou valores menores de argila e maiores de areias, em virtude da maior energia erosiva do escoamento (Tabela 4).

Segundo McGregor et al. (1990), perdas de matéria orgânica do solo e nutrientes associados são de grande relevância na eutrofização da água de drenagem. Os resultados de perdas de $\mathrm{P}$ associado à presença de corpos de água à jusante da área experimental sugerem um risco potencial de $\mathrm{P}$ na eutro-

Tabela 2. Características químicas dos diferentes horizontes do Argissolo Vermelho-Amarelo descrito no local do ensaio.

\begin{tabular}{|c|c|c|c|c|c|c|c|c|c|c|c|}
\hline \multirow{2}{*}{ Horizontes } & \multirow{2}{*}{ Carbono } & \multirow[t]{2}{*}{$\mathrm{pH}$} & \multirow[t]{2}{*}{$\mathrm{P}$} & \multirow[t]{2}{*}{ K } & \multirow[t]{2}{*}{$\mathrm{Al}$} & \multirow[t]{2}{*}{$\mathrm{Ca}$} & \multirow[t]{2}{*}{$\mathrm{Mg}$} & \multirow[t]{2}{*}{$\mathrm{H}+\mathrm{Al}$} & \multirow[t]{2}{*}{ SB } & \multicolumn{2}{|c|}{ CTC } \\
\hline & & & & & & & & & & Efetiva & Total \\
\hline & $--\left(\right.$ dag kg $\left.^{-1}\right)--$ & & $--(\mathrm{m}$ & $\left(m^{-3}\right)--$ & & - & - & - $(\mathrm{cmol}$ & $\left.m^{-3}\right)$ & $-\cdots$ & - \\
\hline Ap & 2,8 & 5,7 & 2,0 & 113,5 & 0,2 & 3,4 & 0,6 & 6,6 & 4,3 & 4,5 & 11,1 \\
\hline $\mathrm{AB}$ & 2,7 & 5,9 & 0,1 & 60,0 & 0,1 & 2,8 & 0,6 & 4,1 & 3,5 & 3,5 & 7,7 \\
\hline $\mathrm{B}_{\mathrm{t} 1}$ & 2,8 & 5,6 & 0,2 & 37,0 & 0,0 & 2,5 & 0,4 & 2,7 & 3,0 & 3,0 & 5,7 \\
\hline
\end{tabular}


fização. As perdas de MOS podem ainda resultar em perda de estabilidade de agregados (Oades, 1984), acelerando a erosão. Valores de correlação positiva mais baixa $(0,592)$ entre os teores de areia e o conteúdo de P perdido por erosão sugerem uma certa associação de $\mathrm{P}$ inorgânico com frações grosseiras (matéria orgânica residual ou nódulos de Fe em tamanho de areia). Perdas associadas de P e matéria orgânica do solo em sedimentos foram reportadas por Hernani et al. (1999).

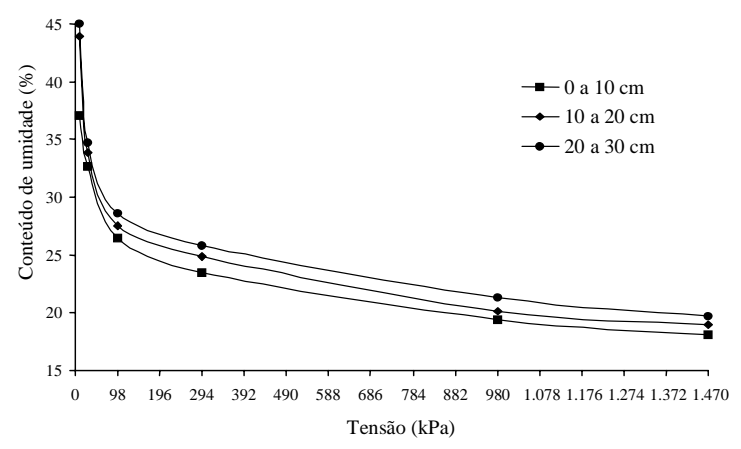

Figura 2. Curva de retenção de água no solo nas três diferentes profundidades.
Com respeito à qualidade da matéria orgânica, os dados do fracionamento do material coletado evidenciaram uma concentração maior de fração humina, seguida das frações ácido húmico e ácido fúlvico (Tabela 6). Esse fato evidencia uma perda seletiva da fração mais solúvel (fúlvica), pelo escoamento superficial, e uma permanência relativa das frações mais humificadas ao longo da encosta. Essa perda seletiva pode ser melhor verificada quando se compara a parcela residual com 100\% de cobertura (com 19\% de ácido fúlvico (AF) e $41 \%$ de humina (HUM)) e o solo descoberto ( $3 \%$ AF e $88 \%$ HUM); assim, a mobilização da fração mais solúvel da matéria orgânica e a retenção no Bidim das frações mais humificadas denota uma acentuada perda de carbono solúvel nos solos sob erosão acelerada, que pode ocasionar acentuada perda de CTC nesses solos, altamente dependentes da matéria orgânica (Schaefer et al., 1999), além de favorecer a eutrofização dos rios e lagos a jusante.

Quanto ao encrostamento e porosidade, as observações micropedológicas dos blocos polidos e nas medidas de macroporosidade mostraram uma aparente desuniformidade subsuperficial no local de

Tabela 3. Perda absoluta de nutrientes $\left(\mathrm{g} \mathrm{ha}^{-1}\right)$ e matéria orgânica $\left(\mathrm{kg} \mathrm{ha}^{-1}\right)$, em razão da porcentagem de cobertura do solo, na intensidade de chuva de $60 \mathrm{~mm} \mathrm{~h}^{-1}$, em média das três primeiras (M1-3) e das três últimas (M4-6) coletas ${ }^{(1)}$.

\begin{tabular}{|c|c|c|c|c|c|c|c|c|c|c|}
\hline \multirow{2}{*}{$\begin{array}{l}\text { Cobertura } \\
\text { do solo }(\%)\end{array}$} & \multicolumn{2}{|c|}{$\mathrm{P}$} & \multicolumn{2}{|c|}{$\mathrm{K}^{+}$} & \multicolumn{2}{|c|}{$\mathrm{Ca}^{2+}$} & \multicolumn{2}{|c|}{$\mathrm{Mg}^{2+}$} & \multicolumn{2}{|c|}{ MO } \\
\hline & M1-3 & M4-6 & M1-3 & M4-6 & M1-3 & M4-6 & M1-3 & M4-6 & M1-3 & M4-6 \\
\hline & & & & - (g l & -1) ------ & & & & ---- (kg & $\left.{ }^{-1}\right)-\cdots$ \\
\hline 0 & 40,4 & 41,8 & 238,5 & 203,8 & $2.168,0$ & $1.742,7$ & 245,3 & 215,4 & 64,2 & 53,9 \\
\hline 20 & 23,8 & 26,9 & 176,6 & 137,7 & $1.638,2$ & $1.190,4$ & $1.998,9$ & 141,2 & 77,5 & 45,2 \\
\hline 40 & 15,2 & 19,7 & 111,3 & 127,8 & 888,9 & $1.055,1$ & 102,9 & 120,3 & 36,0 & 38,6 \\
\hline 80 & 6,4 & 10,2 & 45,6 & 43,6 & 425,8 & 467,3 & 48,6 & 60,2 & 17,5 & 16,4 \\
\hline 100 (residual) & 0,0 & 0,0 & 0,0 & 0,0 & 0,0 & 0,0 & 0,0 & 0,0 & 0,0 & 0,0 \\
\hline
\end{tabular}

${ }^{(1)} \mathrm{P}$ : teores de $\mathrm{P}$ extraíveis com Mehlich 2 e convertidos em $\mathrm{g} \mathrm{ha}^{-1}$ de $\mathrm{P} ; \mathrm{Ca}^{2+}, \mathrm{Mg}^{2+}$ : extraídos com $\mathrm{KCl} 1 \mathrm{M}$ e convertidos em g ha ${ }^{-1}$ de Ca ou $\mathrm{Mg}$.

Tabela 4. Perda total de solo após seis coletas e granulometria (teores de areias, silte e argila) nos sedimentos coletados e na parcela residual (após os ensaios) ${ }^{(1)}$.

\begin{tabular}{cccccccc}
\hline Cobertura & Perda & \multicolumn{5}{c}{ Composição relativa } \\
\cline { 3 - 7 } do solo $(\%)$ & $\begin{array}{c}\text { de solo } \\
\left(\mathrm{t} \mathrm{ha}^{-1}\right)\end{array}$ & $\begin{array}{c}\text { Argila } \\
\text { M1-3 }\end{array}$ & $\begin{array}{c}\text { Argila } \\
\text { M4-6 }\end{array}$ & $\begin{array}{c}\text { Silte } \\
\text { M1-3 }\end{array}$ & $\begin{array}{c}\text { Silte } \\
\text { M4-6 }\end{array}$ & $\begin{array}{c}\text { Areia }(\mathrm{G}+\mathrm{F}) \\
\text { M1-3 }\end{array}$ & $\begin{array}{c}\text { Areia }(\mathrm{G}+\mathrm{F}) \\
\text { M4-6 }\end{array}$ \\
\hline 0 & 13,2 & 15,0 & 15,3 & 5,3 & 6,4 & 79,7 & 78,3 \\
20 & 13,0 & 28,7 & 21,0 & 10,7 & 6,3 & 60,6 & 72,7 \\
40 & 11,8 & 27,0 & 20,7 & 6,3 & 7,3 & 66,7 & 72,0 \\
80 & 5,2 & 28,0 & 22,0 & 6,0 & 6,7 & 66,0 & 71,3 \\
100 (residual) & 0,0 & & 41,0 & & 6,0 & & 53,0 \\
\hline
\end{tabular}

(1)M1-3: média das três primeiras coletas; M4-6: média das três últimas coletas; G: grossa; F: fina. 
instalação do experimento, o que afetou os resultados da macroporosidade observadas e, provavelmente, os resultados de perda de solo avaliados, bem como na sua composição (Figura 3). Além disso, há evidências de que a área experimental se apresentava mais adensada na subsuperfície, a partir da parte intermediária da parcela $40 \%$ para a parte inferior, onde foi localizada a parcela com $100 \%$ de cobertura. Essas porções do experimento apresentaram valores de macroporosidade muito reduzidos em subsuperfície $(3,5 \%$ a 4,5\%) em relação às demais parcelas (Tabela 7). Essa heterogeneidade é facilmente explicada pela posição da área experimental na paisagem, por representar o segmento de transição entre a elevação convexa, dominantemente latossólica, e a porção côncava do plano inclinado, que representa a grota, onde ocorrem argissolos. Na verdade, essas porções mais rejuvenescidas apresentam grande variabilidade pedológica, em virtude da natureza deposicional, em leques aluviais de encosta.

Considerando os resultados de macroporosidade como um todo, a porosidade subsuperficial $(10-20 \mathrm{~cm})$ foi sempre maior na parte superior da parcela, independentemente da sua locação, com valores variando de $11,7 \%$ a $20,9 \%$, e excetuando-se a

Tabela 5. Correlações de Pearson entre duas variáveis, em relação às médias das três primeiras e das três últimas aplicações de chuva simulada.

\begin{tabular}{lccc}
\hline $1^{\text {a }}$ Variável & $2^{\text {a }}$ Variável & Correlação & Significância \\
\hline \multicolumn{4}{c}{ Médias das três primeiras coletas } \\
Argila & $\mathrm{P}$ & $-0,7219$ & 0,08 \\
Argila & $\mathrm{K}$ & $-0,6840$ & 0,10 \\
Argila & $\mathrm{Ca}$ & $-0,6345$ & 0,12 \\
Argila & $\mathrm{Mg}$ & $-0,5749$ & 0,15 \\
MO & $\mathrm{P}$ & 0,7974 & 0,05 \\
MO & $\mathrm{K}$ & 0,8480 & 0,03 \\
MO & $\mathrm{Ca}$ & 0,8863 & 0,02 \\
MO & $\mathrm{Mg}$ & 0,9183 & 0,01 \\
\hline \multicolumn{4}{c}{ Médias das três últimas coletas } \\
Argila & $\mathrm{P}$ & $-0,3223$ \\
Argila & $\mathrm{K}$ & $-0,3836$ & 0,29 \\
Argila & $\mathrm{Ca}$ & $-0,2798$ & 0,26 \\
Argila & $\mathrm{Mg}$ & $-0,2622$ & 0,32 \\
MO & $\mathrm{P}$ & 0,8912 & 0,33 \\
MO & $\mathrm{K}$ & 0,8183 & 0,02 \\
MO & $\mathrm{Ca}$ & 0,9264 & 0,02 \\
MO & $\mathrm{Mg}$ & 0,9254 & 0,01 \\
\hline
\end{tabular}

parcela de $100 \%$ de cobertura, a qual não apresentou variação em subsuperfície. Assim, parece haver uma relação entre a argila dispersa oriunda da desagregação pelo impacto da gota e translocada per descendum e o entupimento de poros maiores no segmento inferior da parcela. Esse fenômeno foi agravado pelo cercamento das parcelas e a conseqüente permanência prolongada da água dentro dos limites das mesmas, impondo um retardamento do fluxo saturado com argila dispersa, que seria rapidamente carreado para os cursos d'água ou porções inferiores do terraço, em sistemas abertos.

O desenvolvimento de crostas ou selamento foi evidenciado em todos os solos expostos, pela destruição de agregados, afetando a rugosidade do solo (Figuras 3 e 4). Entre as observações qualitativas dos blocos polidos (Tabela 7), salienta-se a presença generalizada de crosta deposicional em todos os tratamentos, exceto com $100 \%$ de cobertura; além disso, a presença de crosta erosional com pináculos, detectada nos tratamentos de 0 e $20 \%$ de cobertura, indicando que os efeitos da enxurrada no segmento superior da parcela foram bem mais evidentes que nos demais tratamentos. As crostas ou selamentos foram desenvolvidos com a destruição de agrega-

Tabela 6. Valores médios dos teores de carbono total (COT) e das frações húmicas do material de solo $(0-20 \mathrm{~cm})$ coletado (médias das três primeiras e das três últimas coletas).

\begin{tabular}{ccccc}
\hline $\begin{array}{c}\text { Solo do } \\
\text { ensaio } \\
(\%)\end{array}$ & $\begin{array}{c}\text { Fração } \\
\text { de ácido } \\
\text { fúlvico }(\%)\end{array}$ & $\begin{array}{c}\text { Fração } \\
\text { de ácido } \\
\text { húmico }(\%)\end{array}$ & $\begin{array}{c}\text { Fração de } \\
\text { humina } \\
(\%)\end{array}$ & $\begin{array}{c}\mathrm{COT}^{(1)} \\
\left(\mathrm{dag} \mathrm{kg}^{-1}\right)\end{array}$ \\
\hline \multicolumn{5}{c}{ Médias das três primeiras coletas } \\
0 & 3 & 9 & 88 & 1,45 \\
20 & 14 & 24 & 62 & 2,94 \\
40 & 10 & 23 & 67 & 2,03 \\
80 & 12 & 20 & 68 & 2,33 \\
\hline \multicolumn{5}{c}{ Médias das três últimas coletas }
\end{tabular}

\begin{tabular}{rrrrr}
0 & 2 & 10 & 88 & 1,43 \\
20 & 12 & 20 & 68 & 2,13 \\
40 & 5 & 22 & 73 & 1,66 \\
80 & 8 & 18 & 74 & 1,69 \\
\hline 0 residual & 20 & 38 & 42 & 2,43 \\
20 residual & 22 & 40 & 38 & 3,71 \\
40 residual & 17 & 38 & 45 & 2,49 \\
80 residual & 18 & 36 & 46 & 2,43 \\
100 residual & 19 & 40 & 41 & 2,88 \\
\hline
\end{tabular}

(1)Determinado por Walkley-Black (Embrapa, 1997). 

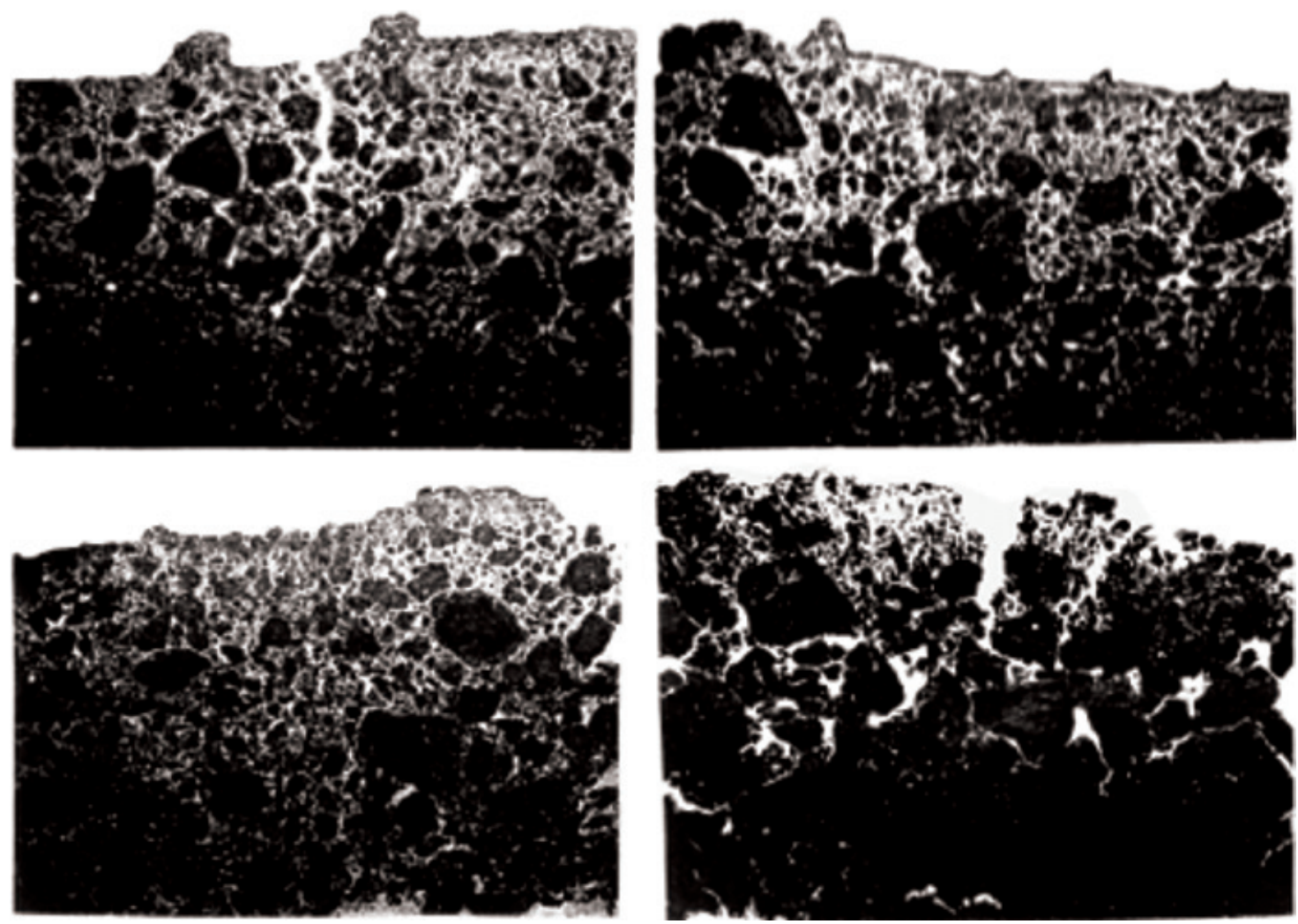

$5 \mathrm{~cm}$

Figura 3. Fotografias em filme sensível ao UV de blocos polidos selecionados na parte superior das parcelas, evidenciando a porosidade (parte clara) e agregados (parte escura), além de pináculos formados por erosão e desenvolvimento de selamento superficial.

Tabela 7. Características micropedológicas dos blocos polidos ${ }^{(1)}$.

\begin{tabular}{|c|c|c|c|c|c|c|c|c|}
\hline \multirow{3}{*}{$\begin{array}{c}\text { Cobertura } \\
(\%)\end{array}$} & \multicolumn{4}{|c|}{ Macroporos (\%) } & \multirow{3}{*}{$\begin{array}{c}\text { Crosta } \\
\text { deposicional }\end{array}$} & \multirow{3}{*}{$\begin{array}{c}\text { Crosta } \\
\text { erosional com } \\
\text { pináculos }\end{array}$} & \multirow{3}{*}{$\begin{array}{l}\text { Descontinuidade } \\
\text { crosta/matriz }\end{array}$} & \multirow{3}{*}{$\begin{array}{c}\text { Poros e vazios } \\
\text { não conectados }\end{array}$} \\
\hline & \multicolumn{2}{|c|}{$\begin{array}{l}\text { Parte superior } \\
\text { da parcela }\end{array}$} & \multicolumn{2}{|c|}{$\begin{array}{l}\text { Parte inferior } \\
\text { da parcela }\end{array}$} & & & & \\
\hline & $0-10 \mathrm{~cm}$ & $\overline{10-20 \mathrm{~cm}}$ & $0-10 \mathrm{~cm}$ & $\overline{10-20 \mathrm{~cm}}$ & & & & \\
\hline 0 & 19,2 & 18,8 & 20,4 & 15,7 & XX & XXXX & Presente na parte baixa & XXX \\
\hline 20 & 21,2 & 20,9 & 18,9 & 10,6 & XX & XXXX & & $\mathrm{X}$ \\
\hline 40 & 20,4 & 18,6 & 20,9 & 3,5 & - & $X^{(2)}$ & Forte na parte baixa & XXX \\
\hline 80 & 19,2 & 14,1 & 21,4 & 7,7 & $\mathrm{XX}$ & XX & & XXXX \\
\hline 100 & 17,5 & 4,5 & 22,3 & 4,5 & - & - & Forte & XXXX \\
\hline
\end{tabular}

${ }^{(1)} \mathrm{X}$ : raro; XX: comum; XXX: muito comum; XXXX: abundante. ${ }^{(2)}$ Ausente na parte inferior.

dos, o que afetou a infiltração do solo (Magunda et al., 1997; Pruski et al., 1997).

A inesperada descontinuidade observada entre a parte superior da crosta delgada no tratamento com $100 \%$ de cobertura (Figura 4) pode ser atribuída ao peso do Bidim encharcado após os eventos de chu- va simulada, propiciando pressão mecânica uniforme e reempacotamento dos agregados do solo, em regime de umidade que favoreceu a adesão mais forte de partículas de argila, de natureza caulinítica, e menor variação de umedecimento e secagem neste solo. Esse fenômeno é reportado em condições ex- 


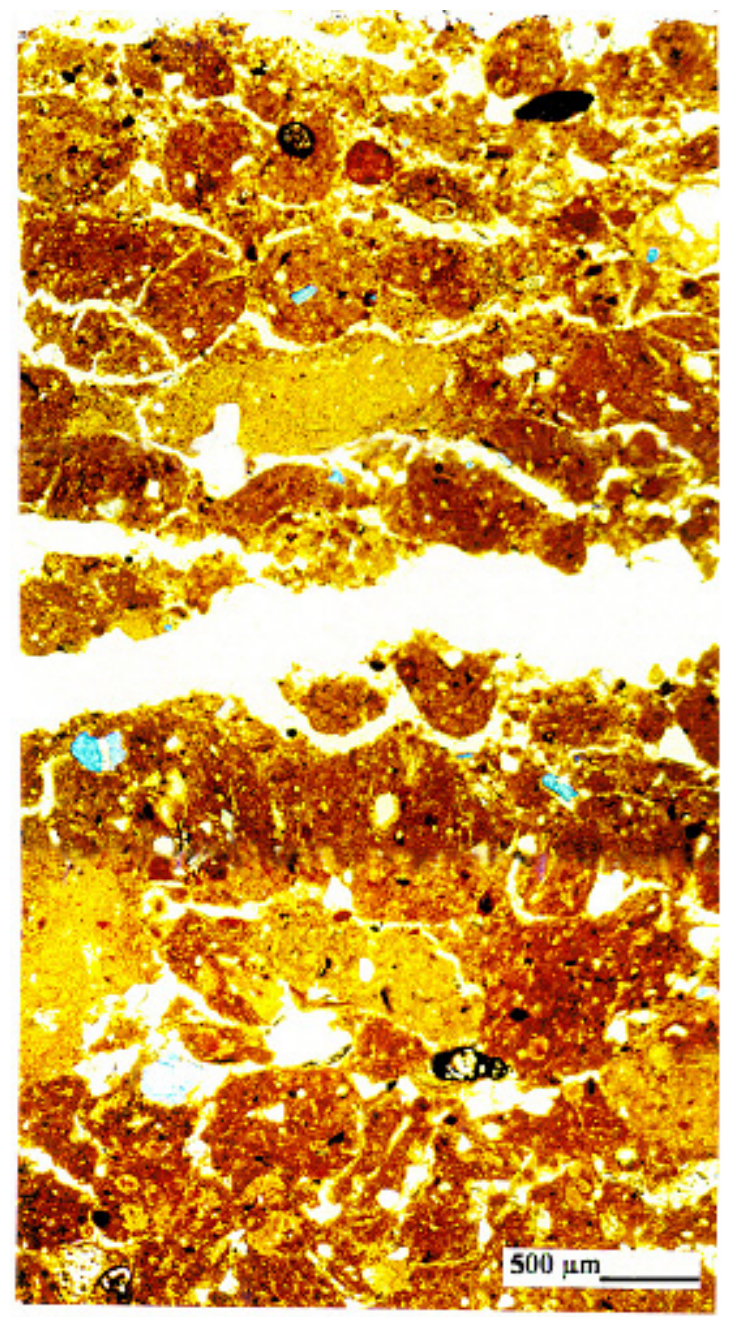

Figura 4. Fotomicrografia do detalhe da crosta erosional desenvolvida nos primeiros centímetros do solo, no tratamento com $0 \%$ de cobertura (solo exposto). Notam-se poros planares paralelos a superfície do solo, e deformação dos agregados.

perimentais por Tessier et al. (1990). No caso de chuva simulada, é possível que a coalescência dos agregados em blocos, de maior tamanho, tenha se efetuado com a participação de argila dispersa, translocada poucos centímetros abaixo da superfície. A Figura 4 ilustra a fotomicrografia do horizonte superficial do solo totalmente exposto, com desenvolvimento de crosta erosional e poros planares, paralelos à superfície, típicos do selamento em solos cauliníticos (Faria et al., 1998).

\section{Conclusões}

1. As perdas absolutas de nutrientes seguem a ordem $\mathrm{Ca}>\mathrm{Mg}>\mathrm{K}>\mathrm{P}$ em todas as coletas, acompanhando a ordem relativa dos teores trocáveis do solo, sendo positivas e significativamente correlacionadas às perdas de matéria orgânica, sem correlacionar com perdas de argila.

2. Perdas totais de solo superiores a $11 \mathrm{t} \mathrm{ha}^{-1}$ nos tratamentos com porcentagem de cobertura variando entre 0 e $40 \%$ decrescem a pouco mais de $5 \mathrm{tha}^{-1}$ com $80 \%$ até zero no tratamento $100 \%$ coberto com Bidim.

3. As perdas de matéria orgânica na enxurrada são preferencialmente em formas mais solúveis e reativas (ácidos fúlvicos).

4. A macroporosidade subsuperficial (10 a $20 \mathrm{~cm}$ ) sugere migração de argila dispersa e entupimento de macroporos sob chuva simulada; nos tratamentos com alguma exposição há desenvolvimento de crosta deposicional; os tratamentos mais expostos apresentam ainda crosta erosional.

\section{Referências}

ALVES, A. G. C.; COGO, N. P.; LEVIEN, R. Relações da erosão do solo com a persistência da cobertura vegetal morta. Revista Brasileira de Ciência do Solo, Campinas, v. 19, n. 1, p. 127-132, 1995.

AMADO, T. J. C.; COGO, N. P.; LEVIEN, R. Eficácia relativa do manejo do resíduo cultural de soja na redução das perdas de solo por erosão hídrica. Revista Brasileira de Ciência do Solo, Campinas, v. 13, n. 2, p. 251-257, 1989.

BERTOL, I.; COGO, N. P.; LEVIEN, R. Cobertura morta e métodos de preparo do solo na erosão hídrica em solo com crosta superficial. Revista Brasileira de Ciência do Solo, Campinas, v. 13, n. 3, p. 373-379, 1989.

BERTONI, J.; LOMBARDI NETO, F. Conservação do solo. São Paulo: Ícone, 1990. 355 p.

BRADFORD, J. M.; FERRIS, J. E.; REMLEY, P. A. Interrill soil erosion processes: I. effect of surface sealing on infiltration, runoff, and soil splash detachment. Soil Science Society of America Journal, Madison, v. 51, n. 6, p. 1566-1571, 1987.

BRAIDA, J. A. Relação da erosão entressulcos, com resíduos em cobertura e erosão em sulcos em solo 
podzólico vermelho escuro. 1994. 152 f. Dissertação (Mestrado) - Universidade Federal de Santa Maria, Santa Maria.

BRESSON, L. M.; VALENTIN, C. Soil surface crust formation: contribution of micromorphology. In: RINGROSE-VOASE, A.; HUMPHREYS, G. S. (Ed.) Soil micromorphology: studies in management and genesis. Amsterdam: Elsevier, 1994. p. 737-762.

EMBRAPA. Centro Nacional de Pesquisa de Solos (Rio de Janeiro, RJ). Manual de métodos de análises de solos. 2. ed. Rio de Janeiro, 1997. 212 p. (Documentos, 1).

FARIA, J. C.; SCHAEFER, C. E.; RUIZ, H. A.; COSTA, L. M. Effects of weed management on sealing development in an ultisol from Brazil. Revista Brasileira de Ciência do Solo, Campinas, v. 22, n. 4, p. 731-742, 1998.

HAYES, M. H. B.; MacCARTHY, P.; MALCOLM, R. L.; SWIFT, R. S. The search for structure: setting the scene In: HAYES, M. H. B. (Ed.). Humic substances II: in search of structure. Chichester: J. Wiley, 1989. p. 3-33.

HERNANI, L. C.; KURIHARA, C. H.; SILVA, W. M. Sistemas de manejo de solo e perdas de nutrientes e matéria orgânica por erosão. Revista Brasileira de Ciência do Solo, Campinas, v. 23, p. 145-154, 1999.

HERNANI, L. C.; SAKAI, E.; LOMBARDI NETO, F.; LEPSCH, I. F. Influência de métodos de limpeza de terreno sob floresta secundária em Latossolo Amarelo do Vale do Ribeira, SP: perdas por erosão. Revista Brasileira de Ciência do Solo, Campinas, v. 11, p. 215-219, 1987.

HERNANI, L. C.; SALTON, J. C.; FABRICIO, A. C.; DEDECEK, R.; ALVES JÚNIOR, M. Perdas por erosão e rendimentos de soja e trigo em diferentes sistemas de preparo de um Latossolo Roxo de Dourados (MS). Revista Brasileira de Ciência do Solo, Campinas, v. 21, p. 667-676, 1997.

KLUTE, A. Methods of soil analysis. 2. ed. Madison, Soil Science Society of America, 1986. part 1.

LAL, R. Soil degradation in the tropics. In: SEGHAL, J.; BLUM, W. E.; GAJBHIYE, K. S. Managing red and lateritic soils for sustainable agriculture. Rotterdam: Balkema, 1998. p. 237-252

LOMBARDI NETO, F.; MARIA, I. C.; CASTRO, O. M.; DECHEN, S. C. F.; VIEIRA, S. R. Efeito da quantidade de resíduos culturais de milho nas perdas de solo e água. Revista Brasileira de Ciência do Solo, Campinas, v. 12, n. 1, p. $71-75,1988$
McGREGOR, K. L.; BENGTSON, R. L.; MUTCHLER, C. K. Surface and incorporated wheat straw effects on interril runoff and soil erosion. Transactions of the ASAE, St. Joseph, v. 33, n. 2, p. 469-474, 1990.

McINTYRE, D. C. Soil splash and the formation of surface crusts by raindrop impact. Soil Science, Baltimore, v. 85, n. 5, p. 261-266, 1958.

MAGUNDA, M. K.; LARSON, W. E.; LINDER, D. R.; NATER, E. A. Changes in microrelief and their effects on infiltration and erosion during simulated rainfall. Soil Technology, Amsterdam, v. 10, n. 1, p. 57-67, 1997.

OADES, J. M. Soil organic matter and structural stability: mechanisms and implications for management. Plant and Soil, Dordrecht, v. 76, p. 319-337, 1984.

OLDEMAN, L. R. The global extent of soil degradation. In: GREENLAND, D. J.; SZALBOLCS, I. (Ed.). Soil resilience and sustainable land use. Wallingford: $\mathrm{CAB}$ International, 1994. p. 99-118.

OLDEMAN, L. R.; HAKKELINK, R. T. A.; SOMBROEK, W. World map of the status of human induced soil degradation: an explanatory note. Amsterdam: International Soil Reference and Information Centre, 1990. 27 p.

PINTO, F. A. Chuvas intensas no estado de Minas Gerais: análises e modelos. 1995. 87 f. Tese (Doutorado) - Universidade Federal de Viçosa, Viçosa.

PRUSKI, F. F.; VENDRAME, V.; OLIVEIRA, E. F. de; BALBINO, L. C.; FERREIRA, P. A.; WERLANG, L.; CARVALHO, L. T. de. Infiltração da água num Latossolo Roxo. Pesquisa Agropecuária Brasileira, Brasília, v. 32 , n. 1, p. 77-84, jan. 1997.

ROTH, C. H.; MEYER, B.; FREDE, G.; DERPSCH, R. The effect of different soybean tillage systems on infiltrability and erosion susceptibility of an Oxisol in Paraná, Brazil. Crop Science, Madison, v. 157, p. 217-226, 1986 .

SCHAEFER, C. E.; ALBUQUERQUE FILHO, M. R.; FERNANDES FILHO, E. I.; ALBUQUERQUE, M. A.; GALVÃO, J. C. C. Micropedological effects of compost and fertilizer incorporation in a clayey ultisol, cultivated with maize, from Coimbra, MG. Revista de Ciências, Caratinga, n. 2, p. 59-64, 1999.

SIDIRAS, N.; ROTH, C. H.; FARIAS, G. S. Efeito da intensidade de chuva na desagregação por impacto de gotas em três sistemas de preparo do solo. Revista 
Brasileira de Ciência do Solo, Campinas, v. 8, n. 2 , p. 251-254, 1984.

TACKETT, J. L.; PEARSON, R. W. Some characteristics of soil crusts formed by simulated rainfall. Soil Science, Baltimore, v. 99, n. 6, p. 407-413, 1964.

TANAKA, U.; YOKOI, Y.; KYUMA, K. Morphological characteristic of soil surface crusts formed under simulated rainfall. Soil Science and Plant Nutrition, Tokyo, v. 38, n. 4, p. 655-664, 1992.

TESSIER, D.; BEAUMONT, A.; PEDRO, G. Influence of clay mineralogy and rewetting rate on clay microstructure. In: DOUGLAS, L. A. (Ed.). Soil micromorphology: a basic and applied science. Amsterdam: Elsevier, 1990. p. 115-122. (Developments in Soil Science, 19).

TOSSEL, R. W.; WALL, G. J.; RUDRA, R. P.; DICKINSON, W. T.; GROENEVELT, P. H. The Guelf rainfall simulator II: a comparison of natural and simulated rainfall characteristics. Canadian Agricultural Engineering, Saskatoon, v. 32, n. 2, p. 215-223, 1990.

VIEIRA, M. J.; COGO, N. P.; CASSOL, E. A. Perdas por erosão em diferentes sistemas de preparo do solo, para a cultura da soja (Glycine max) em condições de chuva simulada. Revista Brasileira de Ciência do Solo, Campinas, v. 2, p. 209-214, 1978.

WILDNER, L. P. Efeito da adição de diferentes resíduos orgânicos nas perdas de solo e água em um solo podzólico vermelho amarelo. 1985. 100 f. Dissertação (Mestrado) - Universidade Federal de Santa Maria, Santa Maria.

YEOMANS, J. C.; BREMNER, J. M. A rapid and precise method for routine determination of organic carbon in soil. Communication in Soil Science and Plant Analysis, New York, v. 19, n. 13, p. 1467-1476, 1988. 